\title{
Genetic population structure of the malaria vector Anopheles baimaii in north-east India using mitochondrial DNA
}

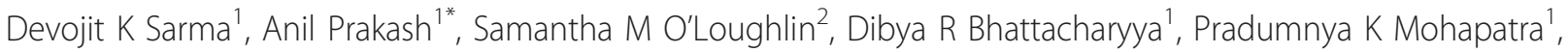
Kanta Bhattacharjee ${ }^{1,3}$, Kanika Das ${ }^{1,4}$, Sweta Singh ${ }^{1}$, Nilanju P Sarma ${ }^{1}$, Gias U Ahmed ${ }^{5}$, Catherine Walton ${ }^{6}$ and Jagadish Mahanta ${ }^{1}$

\begin{abstract}
Background: Anopheles baimaii is a primary vector of human malaria in the forest settings of Southeast Asia including the north-eastern region of India. Here, the genetic population structure and the basic population genetic parameters of An. baimaii in north-east India were estimated using DNA sequences of the mitochondrial cytochrome oxidase sub unit II (COII) gene.

Methods: Anopheles baimaii were collected from 26 geo-referenced locations across the seven north-east Indian states and the COIl gene was sequenced from 176 individuals across these sites. Fifty-seven COll sequences of An. baimaii from six locations in Bangladesh, Myanmar and Thailand from a previous study were added to this dataset. Altogether, 233 sequences were grouped into eight population groups, to facilitate analyses of genetic diversity, population structure and population history.

Results: A star-shaped median joining haplotype network, unimodal mismatch distribution and significantly negative neutrality tests indicated population expansion in An. baimaii with the start of expansion estimated to be $\sim 0.243$ million years before present (MYBP) in north-east India. The populations of An. baimaii from north-east India had the highest haplotype and nucleotide diversity with all other populations having a subset of this diversity, likely as the result of range expansion from north-east India. The north-east Indian populations were genetically distinct from those in Bangladesh, Myanmar and Thailand, indicating that mountains, such as the Arakan mountain range between north-east India and Myanmar, are a significant barrier to gene flow. Within north-east India, there was no genetic differentiation among populations with the exception of the Central 2 population in the Barail hills area that was significantly differentiated from other populations.
\end{abstract}

Conclusions: The high genetic distinctiveness of the Central 2 population in the Barail hills area of the north-east India should be confirmed and its epidemiological significance further investigated. The lack of genetic population structure in the other north-east Indian populations likely reflects large population sizes of An. baimaii that, historically, were able to disperse through continuous forest habitats in the north-east India. Additional markers and analytical approaches are required to determine if recent deforestation is now preventing ongoing gene flow. Until such information is acquired, An. baimaii in north-east India should be treated as a single unit for the implementation of vector control measures.

Keywords: Anopheles baimaii, Cytochrome oxidase II, Southeast Asia, Malaria vector, North-east India, Population genetics

\footnotetext{
* Correspondence: anilprakashin@yahoo.co.in

${ }^{1}$ Regional Medical Research Centre, NE (ICMR), Dibrugarh-786001, Assam,

India

Full list of author information is available at the end of the article
} 


\section{Background}

In the north-eastern region of India (NE India) malaria continues to be a major public health problem with 174,000 cases and 290 deaths recorded during 2010 [1]. Mosquitoes of the Anopheles dirus, Anopheles minimus and Anopheles fluviatilis complexes are the principal malaria vectors in this region. A member of the Dirus complex, Anopheles baimaii, (formerly An. dirus species $\mathrm{D}$ ) is the main vector in forested and forest-fringe areas throughout NE India [2,3]. Anopheles baimaii also occurs widely in Southeast Asia, extending from NE India into the hills of Bangladesh, through Myanmar and into north-western and southern Thailand [4]. Studies using microsatellites, mitochondrial and nuclear sequence data [5] indicated that An. baimaii had a more confined, westerly distribution until it spread eastwards making secondary contact $\sim 62 \mathrm{kyr}$ with a closely related species, An. dirus, on the Thai-Myanmar border. This resulted in introgression of mtDNA from $A n$. baimaii into $A n$. dirus accompanied by a selective sweep of mtDNA. Both $A n$. baimaii and $A n$. dirus have high susceptibility to malaria parasites, high anthropophily and excellent survival rates, making them efficient malaria vectors in the sylvatic environs of Southeast Asia [6-8].

Malaria control with the existing arsenal of antimalarials is problematic due to the emergence of multidrug resistance in Plasmodium falciparum, the predominant malaria parasite in NE India [9]. Vector control is therefore a cost-effective and practical approach to reduce the burden of malaria [10]. Conventional vector control measures such as indoor residual spraying and insecticide-treated nets are effective but operationally difficult, logistically demanding and relatively less effective against exophilic and exophagic vectors such as $A n$. baimaii [4]. Due to such problems, novel vector control strategies are being developed. For example, the wide scale release of genetically modified mosquitoes to render vector populations refractory to malaria parasite infection and improved sterile insect techniques are being considered for An. gambiae and Aedes aegypti [11-15], with the potential to be rolled out to other mosquito vectors if they prove successful. Whether using conventional methods or genetic-based methods of vector control, comprehensive knowledge and understanding of the biology, distribution, genetic population structure and gene flow regime of the vector species is essential for effective vector control. For example, determining genetic structure can help to understand heterogeneities in disease transmission due to genetically distinct vector populations and to predict the spread of genes of interest, such as those involved in insecticide resistance or refractoriness.
Although much is known about the geographical distribution, biology, behaviour and vectorial capacity of An. baimaii in NE India [2,3,16-18], its genetic diversity and population structure have been little studied within this region. Studies of genetic population structure on a broader geographical scale throughout Southeast Asia using mtDNA $[19,20]$, microsatellites $[21]$ and sequences of nuclear genes [5] have revealed low, but significant, structuring in An. baimaii and a lack of population structure in An. dirus. This was attributed to the greater topographical complexity in the western distribution of $A n$. baimaii than the sampled areas of An. dirus from eastern Southeast Asia. Since NE India has a complex topography with large river basins and several different hill ranges, it is hypothesized that there would be significant genetic structuring in An. baimaii in this region. Whereas previous studies were unable to investigate this possibility as they used only a single population in NE India, here an extensive sampling of An. baimaii was conducted throughout the seven constituent states of NE India.

The preponderance of selective sweeps in mitochondrial DNA had led to criticisms for the use of this marker in studies of genetic population structure [22]. Despite such undoubted problems, mitochondrial DNA remains one of the most powerful and reliable tools for detecting population structure and inferring population history due in no small part to its high mutation rate and smaller effective population size than nuclear DNA that leads to more rapid lineage sorting and divergence between populations following their isolation [23]. Although mtDNA originating in An. baimaii underwent a selective sweep in $A n$. dirus following introgression (see above), there is no reason to suspect that mtDNA has undergone a selective sweep in An. baimaii or, if it did, it has been sufficiently long ago that this marker was able to detect population structure in this species on the regional scale studied previously [20]. Therefore, mitochondrial COII gene sequences have been used to assess genetic diversity and determine genetic population structure throughout NE India and consider the implications of our findings for vector control in NE India.

\section{Methods}

Study area, mosquito sampling and species identification The north-east region of India $\left(22^{\circ} 04^{\prime}\right.$ to $29^{\circ} 31^{\prime} \mathrm{N}$ and $89^{\circ} 48^{\prime}$ to $97^{\circ} 25^{\prime} \mathrm{E}$ ), comprising seven administrative states viz. Assam, Arunachal Pradesh, Manipur, Meghalaya, Mizoram, Nagaland and Tripura, experiences a tropical climate with average annual temperature of $25^{\circ} \mathrm{C}$, relative humidity of $70-80 \%$ and rainfall over 2,500 $\mathrm{mm}^{3}$. About $40 \%$ of the $255,128 \mathrm{~km}^{2}$ area of NE India is 
covered with tropical forests. Topographically, the region can be broadly differentiated into the eastern Himalayas to the north, the NE Hills (Meghalaya and Mizoram- Manipur-Kachin hills) to the south, and the Brahmaputra River basin (the Brahmaputra valley) in between [24].

Host-seeking An. dirus s.l. female mosquitoes were collected in human dwellings using Center for Disease Control (CDC) light traps from 26 geo-referenced sites spread through the seven states (Figure 1, Table 1) during 2006-2009. Following morphological identification at the species complex level [25], individual mosquitoes were stored, dehydrated in beam capsules, at $4^{\circ} \mathrm{C}$. Mosquitoes of the Dirus complex were subsequently identified to the species level using an allele specific polymerase chain reaction method [26].

\section{Amplification and sequencing of mtDNA}

A 750 base pair fragment of the mitochondrial COII gene was amplified from 176 individuals of An. baimaii using the AT Leu (5'ATGGCAGATTAGTGCAATGG 3') and BT Lys (5' GTTTAAGAGACCGTACTTG 3') primers [27]. The PCR reactions were performed in 50 $\mu \mathrm{l}$ volumes using a Bio-Rad thermal cycler (California, USA). Each reaction mix included $2.5 \mu \mathrm{l}$ DNA, each primer at $0.5 \mu \mathrm{M}, 3 \mathrm{mM} \mathrm{MgCl} 2,200 \mu \mathrm{M}$ dNTP mix and $1.5 \mathrm{U}$ Taq DNA polymerase in $1 \times$ PCR buffer (RocheScientific, Mannheim, Germany). After a preliminary denaturation step of 5 minutes at $94^{\circ} \mathrm{C}$, there were 35 amplification cycles of $94^{\circ} \mathrm{C}$ for 45 seconds, $50^{\circ} \mathrm{C}$ for 45 seconds and $72^{\circ} \mathrm{C}$ for 60 seconds, followed by a final extension at $72^{\circ} \mathrm{C}$ for seven minutes. The PCR products were purified through High Pure PCR Product Purification Kits (Roche-Scientific, Mannheim, Germany) and sequenced in both directions using Big Dye Terminator V3.1 cycle sequencing kit (Applied Biosystems, USA) on a 3130 XL Genetic Analyser (Applied Biosystems, USA).

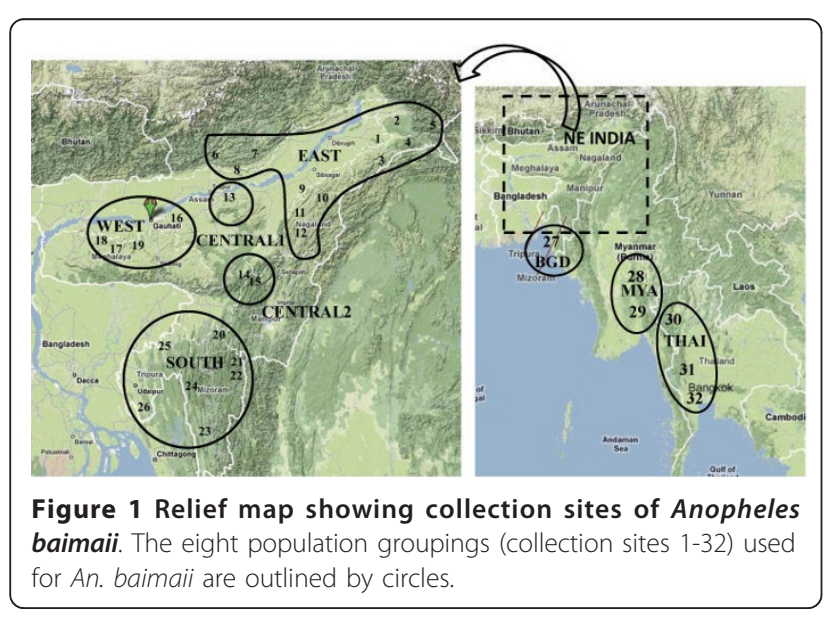

Raw DNA sequences were manually trimmed and edited in BioEdit v 7.0.9 [28].

\section{Analysis of mtDNA variation}

The edited COII sequences were aligned using Clustal W2 [29] and translated into amino acid sequences using the Drosophila mtDNA genetic code in MEGA version 4.0 [30]. The sequences were confirmed as mtDNA COII by comparison with the Anopheles gambiae sequence available in NCBI GeneBank. Information on polymorphic sites, haplotype diversity (hd), frequency of each haplotype, nucleotide diversity $(\pi)$ and $\theta$ s i.e. $\theta$ based on the expected number of segregating sites in a population, was extracted using DnaSP 5.0 [31]. The best model of nucleotide substitution was determined using ModelTest 3.5 [32]. The hierarchical likelihood tests and Akaike Information Criteria (AIC) [33] agreed that the HKY (Hasegawa, Kishino and Yano) model fitted the data best (Log Likelihood -1592.918; AIC 3199.837). This model was used in further analyses as appropriate. However, in Arlequin 3.1 [34] the Tamura and Nei model of evolution [35], being closest to the HKY model, was used.

\section{Population genetic structure}

As there were many sampled sites throughout NE India, spatial analysis of molecular variance (SAMOVA) [36] was used to identify groups of populations that are geographically homogeneous and maximally differentiated from each other without assuming any prior association between populations. The algorithm identifies the optimal number of groups of populations $(\mathrm{k})$ by maximizing $\mathrm{F}_{\mathrm{CT}}$ (the proportion of total genetic variance due to differences among groups of populations) and minimizing $\mathrm{F}_{\mathrm{SC}}$ (genetic differentiation among populations within groups). The SAMOVA analysis was run using 10,000 simulated annealing steps from each of 100 sets of initial starting conditions for $\mathrm{k}=2-24$.

Analysis of molecular variance (AMOVA) for the optimal groups was carried out in Arlequin 3.1. AMOVA takes into account the number of molecular differences between haplotypes in an analysis-of-variance framework equivalent to F-statistics. Pairwise $\mathrm{F}_{\mathrm{ST}}$ values were calculated in Arlequin 3.1 and their significance was tested by 1,000 permutations. To test if the pattern of population differentiation followed an isolation-by-distance model $[37,38]$, a Mantel test was conducted in Arlequin 3.1. This used a matrix of linearized pair-wise genetic distances, estimated by $\mathrm{F}_{\mathrm{ST}}\left[\mathrm{F}_{\mathrm{ST}} / 1-\mathrm{F}_{\mathrm{ST}}\right]$ with corresponding geographic distances among populations calculated using the software Geographic Distance Matrix Generator version 1.2.3 [39].

Spatial structuring within NE India was assessed using the Spatial Analysis of Shared Alleles (SAShA) method 
Table 1 Collection sites and population groupings of Anopheles baimaii in NE India, Bangladesh, Myanmar and Thailand

\begin{tabular}{|c|c|c|c|c|}
\hline Population Name & $\begin{array}{l}\text { Name of the } \\
\text { collection sites }\end{array}$ & Site no. & $\begin{array}{l}\text { Coordinates } \\
\text { (N/E) }\end{array}$ & $\begin{array}{l}\text { No. of An. baimaii } \\
\text { individuals sequenced }\end{array}$ \\
\hline \multirow[t]{13}{*}{ EAST } & Soraipung Forest (AS) & 1 & $\mathrm{~N} 27^{\circ} 23^{\prime} \mathrm{E} 95^{\circ} 34^{\prime}$ & 9 \\
\hline & Tengapani Forest (AP) & 2 & $\mathrm{~N} 27^{\circ} 46^{\prime} \mathrm{E} 95^{\circ} 58$ & 8 \\
\hline & Deomali (AP) & 3 & $\mathrm{~N} 27^{\circ} 09^{\prime} \mathrm{E} 95^{\circ} 28^{\prime}$ & 9 \\
\hline & Jairampur (AP) & 4 & $\mathrm{~N} 27^{\circ} 20^{\prime} \mathrm{E} 96^{\circ} 00^{\prime}$ & 4 \\
\hline & Miao (AP) & 5 & $\mathrm{~N} 27^{\circ} 29^{\prime} \mathrm{E} 96^{\circ} 10^{\prime}$ & 1 \\
\hline & Kameng Bari (AP) & 6 & $\mathrm{~N} 27^{\circ} 04^{\prime} \mathrm{E} 92^{\circ} 25^{\prime}$ & 2 \\
\hline & Pukke Tiger Reserve (AP) & 7 & $\mathrm{~N} 27^{\circ} 03^{\prime} \mathrm{E} 92^{\circ} 36^{\prime}$ & 3 \\
\hline & Nameri National Park (AP) & 8 & $\mathrm{~N} 26^{\circ} 90^{\prime} \mathrm{E} 92^{\circ} 95^{\prime}$ & 34 \\
\hline & Titabor (AS) & 9 & $\mathrm{~N} 26^{\circ} 36^{\prime} \mathrm{E} 94^{\circ} 17^{\prime}$ & 1 \\
\hline & Bhandari (NL) & 10 & $\mathrm{~N} 26^{\circ} 17^{\prime} \mathrm{E} 94^{\circ} 10^{\prime}$ & 8 \\
\hline & Dimapur (NL) & 11 & $\mathrm{~N} 25^{\circ} 54^{\prime} \mathrm{E} 93^{\circ} 44^{\prime}$ & 1 \\
\hline & Medziphema (NL) & 12 & $\mathrm{~N} 25^{\circ} 50^{\prime} \mathrm{E} 93^{\circ} 52^{\prime}$ & 12 \\
\hline & \multicolumn{2}{|c|}{ EAST Total } & & 92 \\
\hline$\overline{\text { CENTRAL } 1}$ & Kaziranga National Park (AS) & 13 & $\mathrm{~N} 26^{\circ} 34^{\prime} \mathrm{E} 93^{\circ} 10^{\prime}$ & 10 \\
\hline \multirow[t]{3}{*}{ CENTRAL 2} & Jatinga (AS) & 14 & $\mathrm{~N} 25^{\circ} 11^{\prime} \mathrm{E} 93^{\circ} 02^{\prime}$ & 4 \\
\hline & Jiribam (MN) & 15 & $\mathrm{~N} 24^{\circ} 47^{\prime} \mathrm{E} 93^{\circ} 12^{\prime}$ & 3 \\
\hline & \multicolumn{2}{|c|}{ CENTRAL2 Total } & & 7 \\
\hline \multirow[t]{5}{*}{ WEST } & Kamrup (AS) & 16 & $\mathrm{~N} 26^{\circ} 17^{\prime} \mathrm{E} 91^{\circ} 92^{\prime}$ & 19 \\
\hline & William Nagar (ML) & 17 & $\mathrm{~N} 25^{\circ} 32^{\prime} \mathrm{E} 90^{\circ} 37^{\prime}$ & 8 \\
\hline & Tura (ML) & 18 & $\mathrm{~N} 25^{\circ} 51^{\prime} \mathrm{E} 90^{\circ} 22^{\prime}$ & 1 \\
\hline & Aradonga (ML) & 19 & $\mathrm{~N} 25^{\circ} 55^{\prime} \mathrm{E} 90^{\circ} 56^{\prime}$ & 2 \\
\hline & \multicolumn{2}{|c|}{ WEST Total } & & 30 \\
\hline \multirow[t]{8}{*}{ SOUTH } & Kolasib (MZ) & 20 & $\mathrm{~N} 24^{\circ} 14^{\prime} \mathrm{E} 92^{\circ} 42^{\prime}$ & 2 \\
\hline & Lengpui (MZ) & 21 & $\mathrm{~N} 22^{\circ} 83^{\prime} \mathrm{E} 92^{\circ} 63^{\prime}$ & 5 \\
\hline & Thenzwal (MZ) & 22 & $\mathrm{~N} 23^{\circ} 19^{\prime} \mathrm{E} 92^{\circ} 45^{\prime}$ & 1 \\
\hline & Tlabung (MZ) & 23 & $\mathrm{~N} 22^{\circ} 53^{\prime} \mathrm{E} 92^{\circ} 53^{\prime}$ & 8 \\
\hline & Dumpa Tiger Reserve (MZ) & 24 & $\mathrm{~N} 23^{\circ} 42^{\prime} \mathrm{E} 92^{\circ} 29^{\prime}$ & 10 \\
\hline & Kailasahar (TR) & 25 & $\mathrm{~N} 24^{\circ} 20^{\prime} \mathrm{E} 92^{\circ} 01^{\prime}$ & 5 \\
\hline & Sabroom (TR) & 26 & $\mathrm{~N} 23^{\circ} \mathrm{O}^{\prime} \mathrm{E} 91^{\circ} 43^{\prime}$ & 6 \\
\hline & \multicolumn{2}{|c|}{ SOUTH Total } & & 37 \\
\hline NE India & & & & 176 \\
\hline $\mathrm{BGD}$ & Chaklapunjee & 27 & $\mathrm{~N} 21^{\circ} 92^{\prime} \mathrm{E} 92^{\circ} 17^{\prime}$ & 6 \\
\hline \multirow[t]{3}{*}{ MYA } & Myaing & 28 & $\mathrm{~N} 19^{\circ} 19^{\prime} \mathrm{E} 97^{\circ} 14^{\prime}$ & 7 \\
\hline & Kyauk & 29 & $\mathrm{~N} 16^{\circ} 61^{\prime} \mathrm{E} 98^{\circ} 24^{\prime}$ & 7 \\
\hline & \multicolumn{2}{|c|}{ MYA Total } & & 14 \\
\hline \multirow[t]{4}{*}{ THAI } & Maesod & 30 & $\mathrm{~N} 16^{\circ} 59^{\prime} \mathrm{E} 98^{\circ} 68^{\prime}$ & 12 \\
\hline & Kanchanaburi & 31 & $\mathrm{~N} 14^{\circ} 33^{\prime} \mathrm{E} 98^{\circ} 99^{\prime}$ & 14 \\
\hline & Ratchaburi & 32 & N135ㅇ' E99³6' & 11 \\
\hline & \multicolumn{2}{|c|}{ THAI Total } & & 37 \\
\hline Overall Total & & & & 233 \\
\hline
\end{tabular}

AS- Assam, AP- Arunachal Pradesh, NL- Nagaland, MN- Manipur, ML- Meghalaya, MZ- Mizoram, TR- Tripura, BGD- Bangladesh, MYA- Myanmar, THAI- Thailand 
[40]. This method is based on the premise that if lineages are evolving locally then the same alleles are expected to co-occur in the same location more often than expected by chance. SAShA detects structure by testing if alleles are more geographically restricted than expected under panmixia by testing if the observed mean of geographical distances between every pair of identical alleles is less than the expected mean assuming panmixia. The expected mean is estimated from the mean of the geographical distances between all pairs of alleles.

A rarefaction method, as commonly used in ecological studies to estimate species diversity, was modified according to Colwell et al [41] to estimate the total number of haplotypes present in the NE Indian populations. In this modification, populations (localities) were treated as "samples" and haplotypes treated as "species". EstimateS 8.2.0 [42] was used to generate haplotype accumulation curves under the assumption of equal sampling effort across populations although it was noted that the studied sample sizes differed between localities. Accuracy of the method will also be reduced if populations vary significantly in haplotype diversity. Despite these considerations, the asymptote of the haplotype accumulation curve provides a reasonable enough estimate of the total number of haplotypes for the purposes here.

\section{Genealogical relationships and population history of mtDNA haplotypes}

A haplotype network was constructed using the median joining (MJ) algorithm [43] in NETWORK 4.5. This method was used as it performs well when there are unsampled internal node haplotypes in the network [44] as occurs here due to the high diversity and high number of haplotypes present. The frequency distribution of the number of pair-wise differences between haplotypes, known as a mismatch distribution, is smooth and unimodal in a recently expanded population [45]. To test if $A n$. baimaii in NE India has undergone expansion, a mismatch distribution was calculated in Arlequin 3.1 and compared with the expectations of the sudden expansion model. The time of expansion was estimated under the sudden expansion model assuming the mutation rate of $1.15 \times 10^{-8} /$ site/year as used by Morgan et al [5] and a generation time of 0.1 years reported for Anophelines (Maharaj, 2003) [46].

To test the null model of neutral mutation and constant population size Tajima's D [47] and Fu's Fs test [48] were used. Tajima's D tests if the estimates of $\theta$ based on the number of segregating sites and $\theta$ based on the average number of pair-wise nucleotide differences are same as expected under the null model. Fu's Fs test [48] assesses if the number of observed alleles is in excess of that expected given the observed level of genetic diversity under the null model. All these neutrality tests were conducted in DnaSP 5.0 and their significance assessed by 10,000 coalescent simulations.

\section{Results}

\section{Sequence variation}

A total of 176 individuals of An. baimaii from 26 sites in NE India were sequenced for 636 bp of the COII gene. No pseudogenes were present as evidenced by the absence of stop codons, the prevalence of synonymous substitutions, low pair-wise divergence and unambiguous electropherograms. All haplotype sequences from NE India have been deposited in GenBank (accession numbers GeneBank:HQ202747 to HQ202801 and GeneBank:HQ650203 to HQ650217). To this dataset 57 COII sequences from one population in Bangladesh $(n=6)$, two populations in Myanmar $(n=14)$ and three populations in Thailand $(\mathrm{n}=37)$ were added from a previous study [20] to enable comparison on a regional scale (Table 1). In the total dataset 83 mutations were found, 71synonymous and 12 non-synonymous with 47 parsimony informative sites. Overall haplotype diversity was high with a total of 103 haplotypes, but it was highest in NE India (89 haplotypes from 176 sequences) with a haplotype diversity of $0.95( \pm 0.012)$ across all NE Indian populations (Table 2).

\section{Population genetic structure}

In the SAMOVA analysis, the $F_{\mathrm{CT}}$ values decreased from $\mathrm{k}=2$ to $\mathrm{k}=24$ indicating an overall lack of genetically distinct population groups. However, the highest value of $F_{\mathrm{CT}}$ was for $\mathrm{k}=2\left(F_{\mathrm{CT}}=0.22\right.$; $\mathrm{p}<$ 0.05 ), in which population 14 (Jatinga, Assam) was separated from all other populations, indicating that population 14 is substantially genetically distinct. There appears to be some genetic distinctiveness of some of the NE Indian populations as they separated one by one from $\mathrm{k}=3$ to $\mathrm{k}=7$ respectively (populations $15,7,1$, $4,2)$. The two most genetically distinct populations, 14 and 15 , are adjacent to one another and not differentiated from each other (pair-wise $F_{\mathrm{ST}} 0.06$, p $<0.4$ ) but there was no discernable spatial pattern among the other genetically distinct populations. From $\mathrm{k}=8$ onwards $F_{\mathrm{SC}}$ was negative indicating no further discernable differentiation among populations within the large group of remaining populations. Up to $\mathrm{k}=16$ the six populations from Bangladesh, Myanmar and Thailand always grouped together further highlighting the distinction between them and the NE Indian populations.

Since SAMOVA was unable to detect obvious population clusters, in order to detect any subtle levels of genetic differentiation using larger sample sizes, samples from all 32 locations were grouped based on their 
Table 2 Summary statistics of Anopheles baimaii population groups

\begin{tabular}{|c|c|c|c|c|c|c|c|c|c|}
\hline $\begin{array}{l}\text { Population } \\
\text { Group }\end{array}$ & $\mathrm{N}$ & Haplotype distribution* & $\mathrm{S}$ & H & $\begin{array}{l}\text { hd } \\
\pm \\
\text { SD }\end{array}$ & $\begin{array}{l}\pi \\
\pm \mathrm{SD}\end{array}$ & $\begin{array}{l}\theta_{S} \\
\pm S D\end{array}$ & $\begin{array}{l}\text { Tajima's } \\
\text { D }\end{array}$ & Fu's Fs \\
\hline EAST & 92 & $\begin{array}{l}1(2), 2,3, \mathbf{4}(\mathbf{2}), 5,6,7, \mathbf{8}(\mathbf{1 3}), \mathbf{9}, 10, \mathbf{1 1}(\mathbf{5}), \mathbf{1 2}(\mathbf{5}), \mathbf{1 3}, \mathbf{1 4}, \mathbf{1 5}, \mathbf{1 6 ( 2 )}, 17,18,19, \\
\mathbf{2 0}(2), 21,22(2), 23,24, \mathbf{2 5}(\mathbf{2}), 26,27, \mathbf{2 8} \mathbf{2 9}, 30, \mathbf{3 1}, 32,33,34,35,36,37,38 \\
39,40, \mathbf{4 1}(2), 42,43(2), \mathbf{4 4}(3), \mathbf{4 5}, \mathbf{4 6}, \mathbf{4 7}(2), 48,49, \mathbf{5 0}, 51,52,53(2), 54, \mathbf{5 5} \\
56,57\end{array}$ & 54 & 57 & $\begin{array}{l}0.972 \\
0.002\end{array}$ & $\begin{array}{l}0.0064 \\
0.0035\end{array}$ & $\begin{array}{l}0.017 \\
0.005\end{array}$ & $-2.057^{* * *}$ & $-25.93^{* * *}$ \\
\hline CENTRAL 1 & 10 & $\mathbf{8}(5), \mathbf{2 0}, \mathbf{2 5}, 58,59,60$ & 8 & 6 & $\begin{array}{l}0.778 \\
0.045\end{array}$ & $\begin{array}{l}0.0031 \\
0.0022\end{array}$ & $\begin{array}{l}0.0044 \\
0.0023\end{array}$ & -1.399 & $-10.84^{* * *}$ \\
\hline CENTRAL 2 & 7 & $8,9,15,16,26,61(2)$ & 11 & 6 & $\begin{array}{l}0.952 \\
0.076\end{array}$ & $\begin{array}{l}0.0076 \\
0.0048\end{array}$ & $\begin{array}{l}0.0071 \\
0.0037\end{array}$ & -0.016 & $-3.29 * *$ \\
\hline WEST & 30 & $\mathbf{8}(9), \mathbf{9}(2), \mathbf{1 2}(\mathbf{4}), \mathbf{1 4}, \mathbf{2 9}, \mathbf{3 1}, \mathbf{4 4}, \mathbf{4 5}, \mathbf{4 7}, 62(2), 63,64,65,66,67,68,69$ & 24 & 17 & $\begin{array}{l}0.899 \\
0.009 \\
\end{array}$ & $\begin{array}{l}0.0053 \\
0.0031\end{array}$ & $\begin{array}{l}0.0095 \\
0.0034 \\
\end{array}$ & $-1.682^{*}$ & $-26.20 * * *$ \\
\hline SOUTH & 37 & $\begin{array}{l}\mathbf{4}, \mathbf{8}(8), \mathbf{9}, \mathbf{1 1}(2), \mathbf{1 2}, \mathbf{1 6}, \mathbf{2 5 ( 2 )}, \mathbf{4 1}, 70,71,72,73,74,75,76,77,78,79,80,81, \\
82,83,84,85,86, \mathbf{8 7}, 88,89\end{array}$ & 40 & 28 & $\begin{array}{l}0.955 \\
0.006\end{array}$ & $\begin{array}{l}0.0062 \\
0.0035\end{array}$ & $\begin{array}{l}0.0150 \\
0.0049\end{array}$ & $-2.183^{* * *}$ & $-25.97 * * *$ \\
\hline \multicolumn{3}{|c|}{ All NE Indian Populations } & 74 & 89 & $\begin{array}{l}0.950 \\
0.012\end{array}$ & $\begin{array}{l}0.0057 \\
0.0003 \\
\end{array}$ & $\begin{array}{l}0.0091 \\
0.0037\end{array}$ & $-2.277^{* *}$ & $-16.09 * * *$ \\
\hline $\mathrm{BGD}$ & 6 & $\mathbf{8}, \mathbf{1 2}(3), \mathbf{5 5}, 90$ & 5 & 4 & $\begin{array}{l}0.800 \\
0.096 \\
\end{array}$ & $\begin{array}{l}0.0030 \\
0.0023 \\
\end{array}$ & $\begin{array}{l}0.0034 \\
0.0021 \\
\end{array}$ & -0.826 & $-4.56^{* * *}$ \\
\hline MYA & 14 & $\mathbf{8}(3), \mathbf{1 2}(4), \mathbf{5 0}, 91(2), 92(2), 93,94$ & 7 & 7 & $\begin{array}{l}0.879 \\
0.027 \\
\end{array}$ & $\begin{array}{l}0.0026 \\
0.0018 \\
\end{array}$ & $\begin{array}{l}0.0035 \\
0.0018 \\
\end{array}$ & -1.019 & $-20.38^{* * *}$ \\
\hline THAI & 37 & $\mathbf{8}(17), \mathbf{1 1}, \mathbf{1 2}(5), \mathbf{2 5}, \mathbf{2 8}, \mathbf{8 7}, 95,96,97,98(3), 99,100,101,102,103$ & 16 & 15 & $\begin{array}{l}0.776 \\
0.006\end{array}$ & $\begin{array}{l}0.0026 \\
0.0017\end{array}$ & $\begin{array}{l}0.0060 \\
0.0021\end{array}$ & $-1.910^{* *}$ & $-27.60^{* * *}$ \\
\hline
\end{tabular}

*Haplotypes in bold occur in more than one population group and the number in parentheses indicates the frequency of a haplotype at a particular site. $\mathrm{N}=$ number of individuals sequenced; $\mathrm{S}=$ number of segregating sites; $\mathrm{H}=$ number of haplotypes; hd = haplotype diversity; $\pi=$ nucleotide diversity per site; $\theta$ s $=$ Genetic diversity estimated from segregating sites; $\mathrm{SD}=$ Standard Deviation

Level of significance is indicated by: ${ }^{*}=<0.05,{ }^{* *}=<0.01,{ }^{* *}=<0.001$

geographical proximity into eight population groups: five population groups from NE India and one population each from Bangladesh, Myanmar and Thailand (Figure 1). Analysis of molecular variance (AMOVA) using these groupings revealed that the majority of variation $(96.8 \%)$ occurred within populations. Pairwise $\mathrm{F}_{\mathrm{ST}}$ among the eight population groups revealed some population structuring at a large spatial scale with the Bangladesh, Myanmar and Thai populations being significantly differentiated from two, three and four of the five NE Indian populations, respectively (Table 3). This corresponds to the signal of isolation by distance also seen on this large spatial scale; the Mantel test using all 32 populations was significant ( $r$
$=0.236, \mathrm{p}<0.02)$. A Mantel test using only the NE Indian populations found no pattern of isolation by distance $(r=0.062, p>0.2)$. There was also no significant differentiation among the NE Indian populations with the sole exception of the Central 2 population group (from the Barail hills area) which comprised populations 14 and 15 , detected by SAMOVA to be the two most genetically distinct sites. The Central 2 group was highly differentiated from the Bangladesh, Myanmar and Thailand population groups (Table 3; e.g. $\mathrm{F}_{\mathrm{ST}}=0.35$ for the Thailand/Central 2 comparison) and differentiated from all other NE Indian groups with the exception of the West NE Indian population group $(\mathrm{p}=0.07)$.

Table 3 Genetic differentiation $\left(F_{S T}\right.$ ) among Anopheles baimaii populations

\begin{tabular}{|c|c|c|c|c|c|c|c|}
\hline & EAST & CENTRAL1 & CENTRAL 2 & WEST & SOUTH & BGD & MYA \\
\hline CENTRAL 1 & -0.009 & & & & & & \\
\hline CENTRAL 2 & $0.071^{*}$ & $0.175^{* *}$ & & & & & \\
\hline WEST & -0.004 & 0.013 & 0.074 & & & & \\
\hline SOUTH & -0.007 & -0.010 & $0.065^{*}$ & -0.002 & & & \\
\hline $\mathrm{BGD}$ & 0.032 & $0.146^{* *}$ & $0.180^{*}$ & 0.026 & 0.060 & & \\
\hline MYA & 0.024 & $0.063^{*}$ & $0.267^{* * *}$ & 0.031 & $0.050^{* *}$ & 0.014 & \\
\hline THAI & $0.055^{* * *}$ & 0.043 & $0.351^{* * *}$ & $0.069 * * *$ & $0.078^{* * *}$ & 0.071 & 0.002 \\
\hline
\end{tabular}

Level of significance is indicated by: ${ }^{*}=p<0.05,{ }^{* *}=p<0.01,{ }^{* * *}=p<0.001$

Sample Sizes: EAST $(n=92)$, CENTRAL1 $(n=10)$, CENTRAL2 $(n=7)$, WEST $(n=30)$, SOUTH $(n=37)$, BGD $(n=6)$, MYA $(n=14)$ and THAI $(n=37)$ 
When lineage diversity is high, as here, it can be hard to detect differentiation since populations tend to comprise alleles from genetically divergent lineages. Since there was some indication from the SAMOVA of genetic distinctiveness within the NE Indian region the Spatial Analysis of Shared Alleles (SAShA) method [40] was used to assess if there was more subtle evidence for population structuring. The SAShA analysis found that the spatial arrangement of COII haplotypes was equidistributed and not statistically different from the expectation under panmixia (observed mean $297.01 \mathrm{~km}$, expected mean $279.76 \mathrm{~km}, \mathrm{p}=0.22$ ). However, haplotype accumulation curves (data not shown) estimated that 250 haplotypes (95\% CI, 160-410) are expected to be present, compared to 89 observed in the NE India, i. e. the majority of haplotypes in northeast India were unsampled. Consequently the SAShA approach has little power to detect structure if it exists since this method relies on being able to resample the same haplotype multiple times. All the methods were therefore unable to detect evidence for genetic structuring throughout the NE India with the exception of populations 14 and 15 in the Central 2 group as noted above.

\section{Genetic diversity}

The genetic diversity and $\theta$ estimates for the eight populations of $A n$. baimaii are presented in Table 2. The NE
Indian populations had higher genetic diversity than the Bangladesh, Myanmar and Thailand populations of $A n$. baimaii with overall values of haplotype diversity (hd) of $0.950 \pm 0.012$, nucleotide diversity of $0.0057 \pm 0.0003$ and $\theta \mathrm{s}$ of $0.0091 \pm 0.0037$. Within NE India the genetically distinct Central 2 population group was similarly genetically diverse to most other groupings but the Central 1 population had markedly lower values of the genetic diversity indices.

\section{Demographic expansion}

The neutrality test statistics (Table 2) were found negative for all the eight populations with some populations having significant values. However, Fu's Fs was found to be significant for all populations. Among the NE Indian populations, both Tajima's D and Fu's Fs statistics were significantly negative (Tajima's D -2.2772, $\mathrm{p}<0.01$; Fu's Fs $-16.085, \mathrm{p}<0.001)$. These negative values indicate population growth with the very high significance of the Fu's Fs test reflecting the power of this statistic [48]. A unimodal mismatch distribution (Figure 2) was also consistent with population expansion as a model of expansion could not be rejected for the observed data $(p=0.27$ and SSD 0.026; $p=0.30)$. It should be noted that all these tests do not distinguish demographic expansion from a selective sweep of mtDNA, which is an expansion of a population of molecules carrying a favoured mutation. The start time of

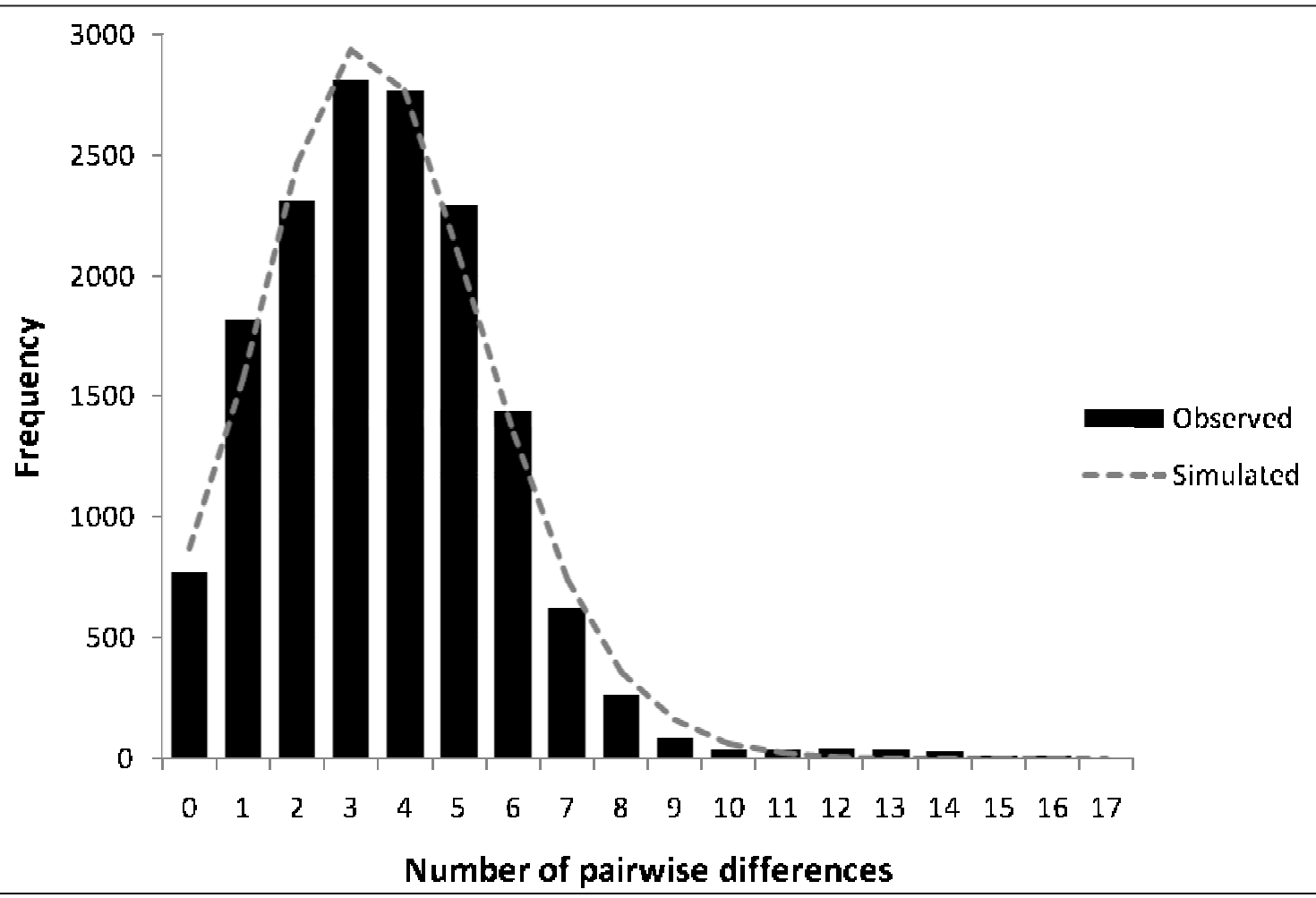

Figure 2 Mismatch distribution among haplotypes of Anopheles baimaii from the NE Indian populations. 
population expansion under the sudden expansion model was estimated using the same mutation rate as in earlier studies to enable a direct comparison with previous estimates for a single NE Indian population of $A n$. baimaii $[5,20]$. However, since there is no calibrated rate for Anopheles, the estimated expansion time should be considered as very approximate. It was found that $A n$. baimaii in the NE India expanded approximately 0.243 million years before present (MYBP) (95\% CI 0.11-0.39) is in broad agreement with the earlier estimates from a single population of about 0.30 MYBP.

\section{Genealogy}

The median joining haplotype network has an overall star-like topology (Figure 3). There are two very high frequency, widespread haplotypes ( $\mathrm{H} 8$ and $\mathrm{H} 12$ ) at the centre of the network, surrounded by many low frequency derived haplotypes, a pattern typically indicative of recent population expansion or a recent selective sweep [49]. The longer lineages were comprised almost exclusively of the NE Indian haplotypes with no pronounced clustering according to population of origin, indicating that the NE Indian populations have similar population histories (Figure 3). Even the highly divergent haplotype (H17) from the East population, that was separated from the core haplotype $\mathrm{H} 8$ by 10 mutations, was confirmed as that of $A n$. baimaii using the PCRbased identification method (see Methods) of Walton et al [26] based on the ribosomal DNA ITS2 region. The presence of two closely related but rare haplotypes (H9 and H16) in the Central 2 population explain the distinctiveness of this population group detected by SAMOVA and pair-wise AMOVA. Duplicate copies of a haplotype restricted to a particular population group i.e. $\mathrm{H} 1, \mathrm{H} 22, \mathrm{H} 43, \mathrm{H} 61$ and H62, were also suggestive of some restrictions to gene flow. However, these were insufficient to give a positive result for the SAShA analysis. The majority of haplotypes from Bangladesh, Myanmar and Thailand were one of the two core haplotypes and the remaining haplotypes from these locations

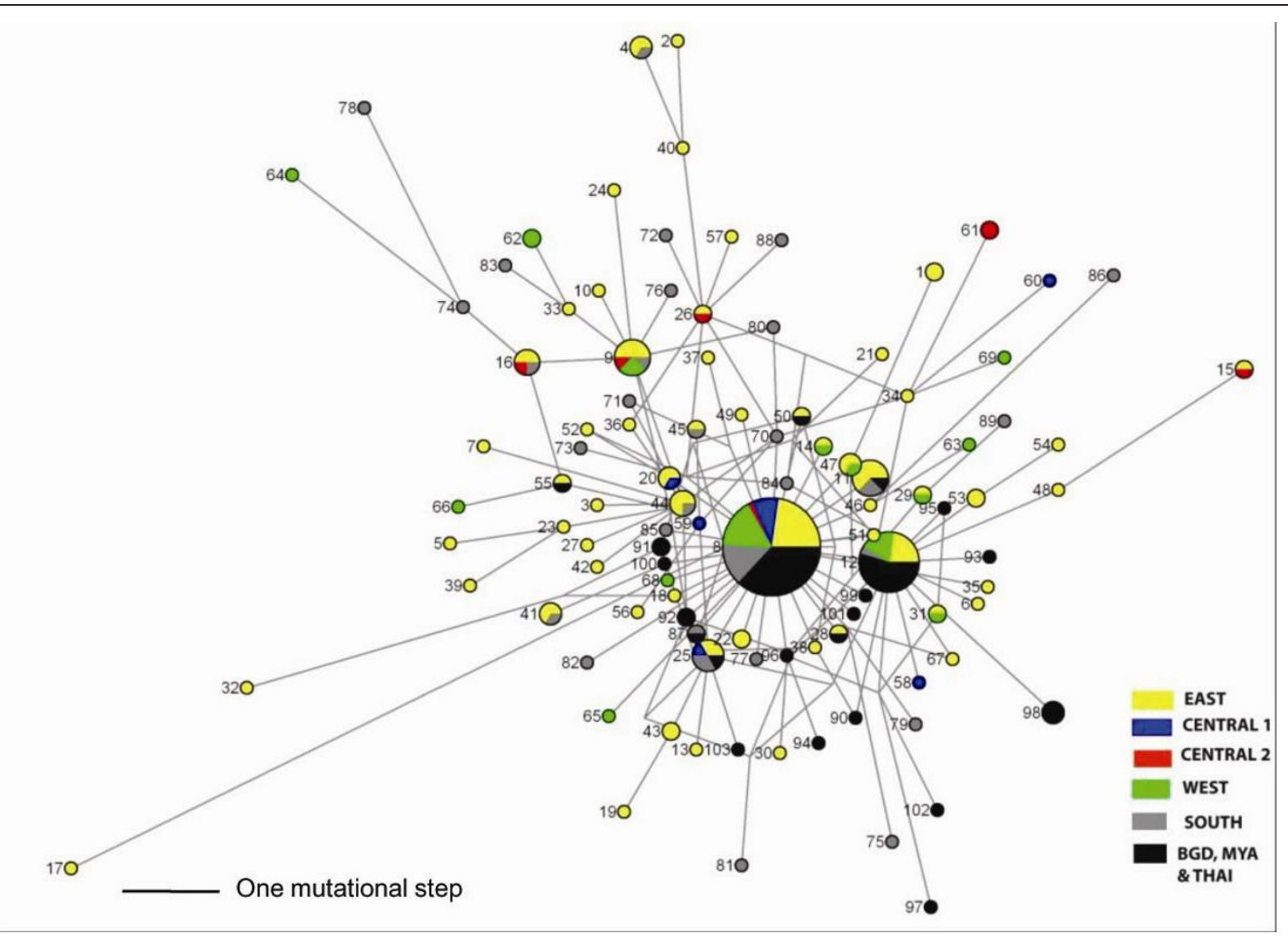

Figure 3 Median joining haplotype network of 103 COII haplotypes of Anopheles baimaii showing the relationships between the haplotypes from the different NE Indian populations and the Bangladesh, Myanmar and Thailand populations. The colour and the size of the circles represent the geographic origin and frequency of each haplotype, respectively. The length of the lines connecting haplotypes is proportional to the number of mutational differences separating the haplotypes. 
generally differed by only one or two mutational steps, indicating a very different demographic history from the NE Indian populations (Figure 3).

\section{Discussion}

This is the first extensive study of An. baimaii in NE India with sampling spanning all seven states. In agreement with earlier studies it was found that An. baimaii in NE India had substantially higher molecular diversity (i.e. $\theta$ s and nucleotide diversity) than populations in Bangladesh, Thailand and Myanmar. This is in accord with NE India being the origin of all extant populations of this species [5]. A further contributing factor to this high genetic diversity may be that much of NE India has acted as a refugium for forest species during Pleistocene glacial cycles when forests were reduced and fragmented across Southeast Asia due to lower temperatures and increased aridity [[50] and refs therein]. The signal of population expansion dating to the late Pleistocene is consistent with this, as during interglacials forests and forest-dependent taxa would expand from refugial areas. The impacts of glacial cycles may have been lower in NE India due to its very high rainfall that results from its unique geography: mountain ranges surrounding valleys such as those of the Brahmaputra and Barak rivers that force the monsoons to rise resulting in very high rainfall [51]. The thesis of NE India as a Pleistocene refugial area is in keeping with the high species diversity of the area $[52,53]$ as high species diversity is often due to long term environmental stability [54].

The wide sampling coverage of our study was able to reveal that not only is there exceptionally high mtDNA diversity of An. baimaii throughout NE India but, as shown by the haplotype network (Figure 3 ), all the mtDNA haplotypes elsewhere in this species are either a limited subset of those present throughout NE India or are only very recently derived from those in NE India. The multiple, distinctive mtDNA lineages within NE India indicate that there has not been a recent selective sweep in NE India itself. Rather, the data are more consistent with the bottlenecking of mtDNA outside of NE India being due to a demographic bottleneck. This is consistent with the inference from combined nuclear and mtDNA data made by Morgan et al [5], that populations of An. baimaii spread from NE India through Myanmar to the Thailand border where they made secondary contact with An. dirus. These therefore further support the inference in Morgan et al [5] that the selective sweep occurs on introgression into An. dirus.

This marked bottlenecking of mtDNA on moving out of NE India results in the observed genetic differentiation of An. baimaii from the populations in Bangladesh, Myanmar and Thailand and indicates the presence of substantial geographical barriers to gene flow from/into NE India. The distribution of An. baimaii [3], was found to be widely present in the foothills and hills of the NE Indian plains. Therefore its absence closer to the Myanmar border (based on this study's sampling in the middle of Mizoram state and in Manipur state) can be attributed to the high elevation and relatively colder temperature of these areas. Since the Arakan mountain range (including the Naga hills and Chin hills) and the Patkai range (including the Lushai (Mizo) hills) that divide NE India from Myanmar average about 2,0003,000 metres, these mountain ranges are therefore likely to be a substantial barrier to dispersal between NE India and Myanmar (Figure 1). As the land between NE India and Bangladesh is of lower elevation it is not clear why the Bangladesh population also appears to be bottlenecked (low genetic diversity and limited distribution of haplotypes across the haplotype network) but we cannot exclude an artifactual effect due to the low sample size from Bangladesh $(\mathrm{n}=6)$.

There is some correlation between geographic and genetic distance on a large spatial scale (i.e. across the countries) but not on a smaller spatial scale (i.e. within NE India) consistent with isolation by distance on a regional scale. However, as there are relatively few sample sites outside of NE India, the possibility that the apparent isolation by distance is due, at least in part, to successive geographical barriers to gene flow cannot be excluded. For example, the Shan Plateau and Tenasserim mountain range with altitudes of up to 1,000 metres that separate Thailand and Myanmar are a likely barrier to dispersal. This is concordant with the observation of no isolation by distance observed within NE India despite the considerable distances involved and the lack of high mountains between the sample sites. Similarly, a previous study using nuclear loci [5] found no differentiation between north and South Thailand, which are also distant but not separated by mountains. Further sampling on a regional geographical scale is required to fully distinguish the alternatives of largescale isolation by distance and montane barriers to gene flow.

Within NE India, the population groups sampled appeared to be somewhat geographically isolated, with a lack of suitable intervening habitat (i.e. primary or minimally disturbed evergreen forests). Despite this, very little genetic structure was apparent, counter to the original hypothesis stated. Instead, the very high genetic diversity and lack of structuring (with the exception of the Central 2 population group from the Barail hills area) indicate large effective population sizes and genetic homogeneity. Given the low sample size of the Central 2 population group (seven individuals) further sample collection and genetic analysis should be done to confirm its genetic distinctiveness. However, the high levels of significance found here indicate that Central 2 really is 
genetically distinct. In addition, there were also some other indications of isolation among the NE Indian populations: the splitting off of several NE Indian populations from $k=2$ to $k=7$; and the low genetic diversity of the Central 1 population that indicates it has undergone a genetic bottleneck and became isolated.

Forests in NE India were until recently contiguous with lowland semi-evergreen forests throughout the Bramaputra valley merging into sub-Himalayan light alluvial semi-evergreen and secondary wet mixed forests in the hilly regions [55]. Large scale fragmentation of these forests occurred only relatively recently, within the last 150-200 years, due to human population increase and economic growth $[52,56]$. Therefore it can likely be considered that the general signal of genetic homogeneity reflects the historical genetic connectivity of $A n$. baimaii populations throughout NE India and that the slight signals of genetic isolation result from recent humanmediated forest fragmentation.

Control of An. baimaii and malaria transmitted by it is a challenging task in areas of its influence, due to its predominant exophagic and exclusive exophilic behaviour, along with its efficient vectorial capacity. Lack of genetic structure and presence of genetic homogeneity, as observed here, may be the likely reasons for its universally efficient vectorial status in this part of India. Use of insecticide treated nets (ITNs) in combination with repellents have been found very effective in controlling malaria transmitted by $A n$. baimaii in the north-east India [57]. At present $A n$. baimaii in this region is susceptible to DDT (used in indoor residual spraying) and pyrthroids (used in ITNs) [58], but in view of the possibility of gene flow among populations of this mosquito, close monitoring of insecticide susceptibility status in NE India is warranted.

\section{Conclusions}

Anopheles baimaii populations from NE India are more genetically diverse and genetically distinct from $A n$. baimaii in the rest of Southeast Asia; the latter likely as a result of high elevations being a barrier to gene flow. Therefore it should not be assumed that biological features recorded for An. baimaii in one region of Southeast Asia necessarily apply to An. baimaii in another region. For example, it was noted that some populations in Myanmar differ with respect to larval habitat choice, breeding in wells in villages rather than in groundwater in the forest $[59,60]$. Within NE India, biological attributes of $A n$. baimaii such as breeding, biting and resting behaviours, response to insecticides, and malaria transmission, appear to be uniform throughout much of the region $[2,16,61]$, consistent with the overall lack of population genetic structuring observed here. If the genetic distinctiveness of the Central 2 population is confirmed by further genetic analysis on larger sample sizes (currently $\mathrm{n}=7$ ), detailed bionomical studies of $A n$. baimaii are needed in the Barail hill range of the NE India to determine if the genetic distinctiveness of the Central 2 population corresponds to any changes in biological traits that affect malaria transmission or vector control. It is important to note that in the Central 2 population areas $A n$. baimaii occurs sympatrically with the closely related, recently reported species $\times$ of the An. dirus complex [3]. Further studies should therefore include a thorough evaluation of the epidemiological significance of both species.

The findings of this study highlight the difficulty of detecting recent structuring in populations when there are very high population sizes and high genetic diversity, as multiple divergent lineages occur in all locations and there will be a substantial time lag before haplotype frequencies vary between populations. The extent of ongoing (rather than historical) gene flow is needed for vector control but determining this will be challenging. It will require the use of multiple markers combined with innovative analytical approaches to provide the power needed to distinguish ongoing gene flow from the potential confounding effects of demographic history.

\section{Acknowledgements}

Funding from Indian Council of Medical Research, Department of Health Research, Government of India is acknowledged with thanks. We appreciate the assistance of A C Rabha, D Dutta, R Sonowal, S Das, K Das and P Thakur. Help by K Rekha Devi and K Narain in sequencing work and logistic support by various officials of the Health Departments of the north-eastern states are sincerely thanked. Authors are thankful to Ryan P Kelly and Tom A Oliver for their technical advice and fruitful discussions on SASha.

\section{Author details}

${ }^{1}$ Regional Medical Research Centre, NE (ICMR), Dibrugarh-786001, Assam, India. 'Department of Ecology and Evolution, Imperial College London, Silwood Park SL5 7PY, UK. ${ }^{3}$ College of Veterinary Sciences, Assam Agriculture University, Guwahati-781022 Assam, India. ${ }^{4}$ Assam Agricultural University, Jorhat - 785013 Assam, India. ${ }^{5}$ Department of Biotechnology, Gauhati University, Guwahati-781014 Assam, India. ${ }^{6}$ Faculty of Life Sciences, University of Manchester, Oxford Road, Manchester M13 9PT, UK.

\section{Authors' contributions}

This study forms part of the PhD thesis work of DKS. DKS collected mosquitoes, performed the data analysis and drafted the manuscript. DKS and $\mathrm{SMO}^{\prime} \mathrm{L}$ performed molecular analyses including PCR and DNA sequencing of the COll gene fragment. AP helped in the field collections, data analysis and in preparation of manuscript. DRB, NPS and SS helped in mosquito collections. KD and KB performed the molecular identification work. PKM and GUA helped in drafting of the manuscript. AP, JM and CW participated in the design of the study, data analysis, draft of manuscript, general supervision of the research group and fund acquisitions. All authors read and approved the final documents.

\section{Competing interests}

The authors declare that they have no competing interests.

Received: 2 December 2011 Accepted: 20 March 2012

Published: 20 March 2012 


\section{References}

1. National Vector Borne Disease Control Programme, Govt. of India, 2010. [http://nvbdcp.gov.in/Doc/Mal-Situation-Aug2011.pdf].

2. Prakash A, Bhattacharyya DR, Mohapatra PK, Mahanta J: Estimation of vectorial capacity of Anopheles dirus (Diptera: Culicidae) in a forestfringed village of Assam (India). Vector Borne Zoonotic Dis 2001, 1:231-237.

3. Prakash A, Sarma DK, Bhattacharyya DR, Mohapatra PK, Bhattacharjee K, Das K, Mahanta J: Spatial distribution and r-DNA second internal transcribed spacer characterization of Anopheles dirus (Diptera: Culicidae) complex species in NE India. Acta Trop 2010, 114:49-54.

4. Obsomer V, Defourny P, Coosemans M: The Anopheles dirus complex: spatial distribution and environmental drivers. Malar J 2007, 6:26.

5. Morgan K, Linton YM, Somboon P, Saikia P, Dev V, Socheat D, Walton C: Inter-specific gene flow dynamics during the Pleistocene-dated speciation of forest-dependent mosquitoes in Southeast Asia. Mol Ecol 2010, 19:2269-2285.

6. Manguin S, Garros C, Dusfour I, Harbach RE, Coosemans M: Bionomics, taxonomy, and distribution of the major malaria vector taxa of Anopheles subgenus Cellia in Southeast Asia: An updated review. Infect Genet Evol 2008, 8:489-503.

7. Sallum MAM, Peyton EL, Wilkerson RC: Six new species of the Anopheles leucosphyrus group, reinterpretation of An. elegans and vector implications. Med Vet Entomol 2005, 19:158-199.

8. Sinka ME, Bangs MJ, Manguin S, Chareonviriyaphap T, Patil AP, Temperley WH, Gething PW, Elyazar IR, Kabaria CW, Harbach RE, Hay SI: The dominant Anopheles vectors of human malaria in the Asia-Pacific region: occurrence data, distribution maps and bionomic précis. Parasit Vectors 2011, 4:89.

9. Mohapatra PK, Namchoom NS, Prakash A, Bhattacharyya DR, Goswami BK, Mahanta J: Therapeutic efficacy of anti-malarials in Indo-Myanmar border areas of Arunachal Pradesh. Indian J Med Res 2003, 118:71-76.

10. Hemingway J, Craig A: New ways to control malaria. Science 2004, 303:1984-1985.

11. James AA: From Control of disease transmission through genetic modification of mosquitoes. In Insect trangenesis: Methods and Applications.. 1 edition. Edited by: Handler AM, James AA. Florida: CRC Press; 2000:319-333.

12. Collins FH, Kamau L, Ranson HA, Vulule JM: Molecular entomology and prospects for malaria control. Bull World Health Organ 2000, 78:1412-1423.

13. Alphey $L$, Beard $C B$, Billingsley $P$, Coetzee $M$, Crisanti $A$, Curtis $C$, Eggleston P, Godfray C, Hemingway J, Jacobs-Lorena M, James AA, Kafatos FC, Mukwaya LG, Paton M, Powell JR, Schneider W, Scott TW, Sina B, Sinden R, Sinkins S, Spielman A, Touré Y, Frank H, Collins FH: Malaria control with genetically manipulated insect vectors. Science 2002, 298:119-121.

14. Christophides GK: Transgenic mosquitoes and malaria transmission. Cell Microbiol 2005, 7:325-333

15. Windbichler N, Menichelli M, Papathanos PA, Thyme SB, Li H, Ulge UY, Horde BT, Baker D, Monnat RJ, Burt A, Crisanti A: A synthetic homing endonuclease-based gene drive system in the human malaria mosquito. Nature 2011, 473:212-215.

16. Prakash A, Bhattacharyya DR, Mohapatra PK, Mahanta J: Indoor biting behaviour of Anopheles dirus, Peyton and Harrison, 1979 in upper Assam, India. Mosa Borne Dis Bull 1997, 14:31-37.

17. Prakash A, Bhattacharyya DR, Mohapatra PK, Mahanta J: Breeding and day resting habitats of Anopheles dirus (Diptera: Culicidae) in Assam. Southeast Asian J Trop Med Public Health 1997, 28:610-614.

18. Prakash A, Bhattacharyya DR, Mohapatra PK, Mahanta J: Malaria transmission risk by the mosquito Anopheles baimai (formerly known as An. dirus species D) at different hours of the night in NE India. Med Vet Entomol 2005, 19:423-427.

19. Walton C, Handley JM, Tun-Lin W, Collins FH, Harbach RE, Baimai V, Butlin RK: Population structure and population history of Anopheles dirus mosquitoes in Southeast Asia. Mol Biol Evol 2000, 17:962-974.

20. O'Loughlin SM, Okabayashi T, Honda M, Kitazoe Y, Kishino H, Somboon P, Sochantha T, Nambanya S, Saikia PK, Dev V, Walton C: Complex population history of two Anopheles diru mosquito species in South-east Asia suggests the influence of Pleistocene climate change rather than human mediated effects. J Evol Biol 2008, 21:1555-1569.
21. Walton C, Handley JM, Collins FH, Baimai V, Harbach RE, Deesin V, Butlin RK: Genetic population structure and introgression in Anopheles dirus mosquitoes in South-east Asia. Mol Ecol 2001, 1:569-580.

22. Galtier N, Nabholz B, Glémin S, Hurst GDD: Mitochondrial DNA as a marker of molecular diversity: a reappraisal. Mol Ecol 2009, 18:4541-4550.

23. Zink RM, Borrowclough GF: Mitochondrial DNA under siege in avian phylogeography. Mol Ecol 2008, 17:2107-2121.

24. Olson D, Dinerstein E: The Global 200: priority ecoregions for global conservation. Annals of the Missouri Botanical Garden 2002, 89:199-224.

25. Das BP, Rajagopal R, Akiyama J: Pictorial key to the species of Indian anopheline mosquitoes. Zoology 1990, 2:131-162.

26. Walton C, Handley JM, Kuvangkadilok C, Collins FH, Harbach RE, Baimai V, Butlin RK: Identification of five species of the Anopheles dirus complex from Thailand using allele-specific polymerase chain reaction. Med Vet Entomol 1999, 13:24-32.

27. Liu H, Beckenbach T: Evolution of the mitochondrial cytochrome oxidase Il gene among 10 orders of insects. Mol Phylogenet Evol 1992, 1:41-52.

28. Hall TA: BioEdit: a user-friendly biological sequence alignment editor and analysis program for Windows 95/98/NT. Nucl Acids Symp Ser 1999, 41:95-98.

29. Larkin MA, Blackshields G, Brown NP, Chenna R, McGettigan PA, McWilliam H, Valentin F, Wallace IM, Wilm A, Lopez R, Thompson JD, Gibson TJ, Higgins DG: ClustalW and ClustalX version 2. Bioinformatics 2007, 23:2947-2948.

30. Tamura K, Dudley J, Nei M, Kumar S: Molecular Evolutionary Genetics Analysis (MEGA) software version 4.0. Mol Biol Evol 2007, 24:1596-1599.

31. Librado P, Rojas J: DnaSP v5: A software for comprehensive analysis of DNA polymorphism data. Bioinformatics 2009, 25:1451-1452.

32. Posada D, Crandall KA: Selecting models of nucleotide substitution: an application to human immunodeficiency virus 1 (HIV-1). Mol Biol Evol 2001, 18:897-906.

33. Akaike $\mathrm{H}$ : A new look at the statistical model identification. IEEE Technol Autom Control 1974, 19:716-723.

34. Excoffier L, Laval G, Schneider S: Arlequin (ver. 3.0): an integrated software package for population genetics data analysis. Evol Bioinform online 2005, 1:47-50.

35. Tamura K, Nei M: Estimation of the number of nucleotide substitutions in the control region of mitochondrial DNA in humans and chimpanzees. Mol Biol Evol 1993, 10:512-526.

36. Dupanloup I, Schneider S, Excoffier L: A simulated annealing approach to define the genetic structure of populations. Mol Ecol 2002, 11:2571-2581.

37. Wright S: Isolation by distance. Genetics 1943, 28:114-138.

38. Slatkin M: Isolation by distance in equilibrium and non-equilibrium populations. Evolution 1993, 47:264-279.

39. Ersts PJ: Geographic Distance Matrix Generator (version 1.2.3), American Museum of Natural History, Center for Biodiversity and Conservation. http:// biodiversityinformatics.amnh.org/open_source/gdmg Accessed on 05-03-11.

40. Kelly RP, Oliver TA, Sivasundar A, Palumbi SR: A method for detecting population genetic structure in diverse, high gene-flow species. J Hered 2010, 101:423-436.

41. Colwell RK, Mao CX, Chang J: Interpolating, extrapolating, and comparing incidence-based species accumulation curves. Ecology 2004, 85:2717-2727.

42. Colwell RK: EstimateS: Statistical estimation of species richness and shared species from samples. Version 8.2. 2009, User's Guide and application published at: http://purl.oclc.org/estimates Accessed on 11-102011

43. Bandelt $H J$, Forster $P$, Röhl A: Median-joining networks for inferring intraspecific phylogenies. Mol Biol Evol 1999, 16:37-48.

44. Cassens I, Mardulyn P, Milinkovitch MC: Evaluating intraspecific "network" construction methods using simulated sequence data: do existing algorithms outperform the global maximum parsimony approach? Sys Biol 2005, 54:363-372.

45. Rogers AR: Genetic evidence for a Pleistocene population explosion. Evolution 1995, 49:608-615.

46. Maharaj R: Life table characteristics of Anopheles arabiensis (Diptera: Culicidae) under simulated seasonal conditions. J Med Ent 2003, 40:737-742.

47. Tajima F: Statistical method for testing the neutral mutation hypothesis by DNA polymorphism. Genetics 1989, 123:585-595. 
48. Fu XY: Statistical tests of neutrality of mutations against population growth, hitchhiking and background selection. Genetics 1997, 147:915-925.

49. Bandelt $\mathrm{H}-\mathrm{J}$, Forster $\mathrm{P}$, Sykes BC, Richards MB: Mitochondrial portraits of human populations using median networks. Genetics 1995, 141:743-753.

50. Morgan $\mathrm{K}$, O'Loughlin SM, Chen B, Linton YM, Thongwat D, Somboon P, Fong MY, Butlin R, Verity R, Prakash A, Htun PT, Hlaing T, Nambanya S, Socheat D, Dinh TH, Walton C: Comparative phylogeography reveals a shared impact of Pleistocene environmental change in shaping genetic diversity within nine Anopheles mosquito species across the Indo-Burma biodiversity hotspot. Mol Ecol 2011, 20:4533-4549.

51. Proctor J, Haridasan K, Smith GW: How far north does lowland tropical rainforests go? Global Ecol Biogeogr Let 1998, 7:141-146.

52. Chatterjee S, Saikia A, Dutta P, Ghosh D, Pangging G, Goswami AK: Biodiversity significance of north-east India. 2006 [http://mdoner.gov.in/ writereaddata/sublink3images/40.pdf], WWF India.

53. Yumnam JY: Rich biodiversity of northeast India needs conservation. Curr Sci 2008, 95:297.

54. Prance GT: Origin and evolution of Amazon flora. Interciencia 1978, 3:207-222.

55. Champion HG, Seth SK: A revised survey of the forest types of India. Government of India Press 1968.

56. Bera SK, Basumatary SK: Proxy climate signals from lacustrine lake sediments of Upper Assam Basin and adjoining foot-hills forests of Arunachal Pradesh (Subansiri district) during Holocene: A comparative palaeecoological assessment. Annual Report Birbal Sahni Institute of Paleobotany, Lucknow; 2008.

57. Prakash A, Bhattacharyya DR, Mohapatra PK, Mahanta J: Insecticide susceptibility status of Anopheles dirus in Assam. J Commun Dis 1998, 30:62.

58. Prakash A, Bhattacharya DR, Mohapatra PK, Baruah U, Phukan A, Mahanta J: Malaria control in a forest camp in oil exploration area of upper Assam. India. National Medical Journal of India 2003, 16:135.

59. Thin Thin Oo, Storch V, Becker N: Studies on the bionomics of Anopheles dirus (Culicidae: Diptera) in Mudon, Mon State, Myanmar. J Vect Ecol 2002, 27:44-54.

60. Minn S, Mya MM, Than SM, Hlaing T, Druilhe P, Queuche F: Well breeding Anopheles dirus and their role in malaria transmission in Myanmar. Southeast Asian I Trop Med Public Health 1999, 30:447-453.

61. Dutta P, Bhattacharyya DR, Khan SA, Sharma CK, Mahanta J: Feeding patterns of Anopheles dirus, the major vector of forest malaria in northeast India. Southeast Asian J Trop Med Public Health 1996, 27:378-381.

doi:10.1186/1475-2875-11-76

Cite this article as: Sarma et al:: Genetic population structure of the malaria vector Anopheles baimaii in north-east India using mitochondrial DNA. Malaria Journal 2012 11:76.

\section{Submit your next manuscript to BioMed Central and take full advantage of:}

- Convenient online submission

- Thorough peer review

- No space constraints or color figure charges

- Immediate publication on acceptance

- Inclusion in PubMed, CAS, Scopus and Google Scholar

- Research which is freely available for redistribution

Submit your manuscript at www.biomedcentral.com/submit 